\title{
A Neuraminidase from Trypanosoma cruzi Removes Sialic Acid from the Surface of Mammalian Myocardial and Endothelial Cells
}

\author{
Peter Libby, Joseph Alroy, and Miercio E. A. Pereira \\ Departments of Medicine and Pathology, Tufts University School of Medicine, Boston, Massachusetts 02111
}

\begin{abstract}
Trypanosoma cruzi causes Chagasic heart disease, a major public health problem in Latin America. The mechanism of interaction of this protozooan parasite with host cells is poorly understood. We recently found that the infective trypomastigote form of $\boldsymbol{T}$. cruzi exhibits neuraminidase activity and can desialylate mammalian erythrocytes. However, it is not known if $T$. cruzi can also modify the surfaces of cardiovascular cells that are directly involved in the most important clinical manifestations of this disease. Accordingly, this study determined whether $T$. cruzi can remove sialic acid from cultured rat myocardial or human vascular endothelial cells. Sialic acid was labeled metabolically with the precursor ${ }^{3} \mathrm{H}-\mathrm{N}$-acetyl-D-mannosamine. Soluble neuraminidase, isolated from intact $T$. cruzi trypomastigotes, caused significant release of labeled material from myocardial cells (e.g., $2,174 \pm 27 \mathrm{dpm} / \mathrm{h}$ vs. spontaneous release of $306 \pm 30 \mathrm{dpm} / \mathrm{h}, n$ $=4, P<0.001)$. Chromatographic analysis showed that the bulk of the radioactivity released by $\boldsymbol{T}$. cruzi neuraminidase was sialic acid. Intact $\boldsymbol{T}$. cruzi trypomastigotes also released sialic acid from metabolically labeled myocardial cells in a concentration-dependent manner. In contrast, a noninfective form of $\boldsymbol{T}$. cruzi, the amastigote, did not desialylate these cells. Galactose oxidase labeling demonstrated newly desialylated glycoproteins on the surface of myocardial cells treated with $\boldsymbol{T}$. cruzi neuraminidase. Desialylation of myocardial cells was confirmed histochemically by the appearance of binding sites for peanut agglutinin, a lectin that binds to complex oligosaccharide moieties after removal of the terminal sialyl residue. $T$. cruzi neuraminidase also removed sialic acid from adult human saphenous vein endothelial cells, as determined by both histochemical and metabolic labeling studies. Thus, infective forms of $T$. cruzi can chemically modify the surfaces of myocardial and vascular endothelial cells by desialylation. This alteration may play a role in the initial interaction of this parasite with these important target cells of the host cardiovascular system.
\end{abstract}

\section{Introduction}

Chagas' disease is endemic in large areas of the southern half of the western hemisphere, and affects more than 10 million people (1). Cardiac abnormalities including biventricular failure, severe brady- or tachyarryhthmias, and aneurysms of the left ventricular

Part of this work was published in abstract form (1984. Circulation 70: II-72).

Address reprint requests to Dr. Libby.

Received for publication 5 June 1985 and in revised form 6 September 1985.

J. Clin. Invest.

(c) The American Society for Clinical Investigation, Inc.

$0021-9738 / 86 / 01 / 0127 / 09 \$ 1.00$

Volume 77, January 1986, 127-135 apex are the most important clinical consequences of this disease (1). Since in the mammalian host Trypanosoma cruzi can only multiply within cells, the parasite's initial interaction with host cells must be essential in the pathogenesis of Chagas' disease. Nogueira and colleagues $(2,3)$ have examined in detail the interaction of this parasite with the macrophage. Others have studied the interaction of $T$. cruzi with certain established cell lines, particularly fibroblasts (4-6). We recently described a neuraminidase activity associated with the surface of infective forms of $T$. cruzi that can remove sialic acid from mammalian erythrocytes both in vitro and in vivo $(7,8)$.

However, none of these previous studies have focused on the interaction of $T$. cruzi with the differentiated cardiovascular cells that are the important targets in the pathogenesis of Chagasic heart disease. The surfaces of myocardial and vascular endothelial cells also contain functionally important sialylated macromolecules that are potential substrates for this enzyme. Accordingly, this study tested whether the neuraminidase associated with infective forms of $T$. cruzi could modify by desialylation the surfaces of intact, functioning mammalian myocardial and vascular endothelial cells in primary culture. Because of the multiple important biological functions of surface sialoglycoproteins and the many consequences of desialylation, such modification might play a role in the interaction of this parasite with these clinically important host cells.

\section{Methods}

Sources and preparations of $T$. cruzi. $T$. cruzi trypomastigotes of two different strains ( $\mathrm{Y}$ and Montalvania) were propagated in cultured bovine aortic smooth muscle cells, prepared as described previously (9). $3-5 \mathrm{~d}$ after initial infection, amastigote forms were harvested from the culture supernatants. Trypomastigote forms were harvested from similar cultures infected for 7-10 d, and were purified on a metrizamide gradient (7). After harvesting the parasites were washed three times in phosphatebuffered saline (PBS; $\mathrm{NaCl}, 150 \mathrm{mM} ; \mathrm{NaPO}_{4}, 10 \mathrm{mM} ; \mathrm{pH} 7.2$ ) and counted in a hemocytometer.

Preparation and assay of $T$. cruzi neuraminidase. A crude preparation of soluble $T$. cruzi neuraminidase was made by incubating trypomastigotes with Dulbecco's modified Eagle's medium (DME) medium at $4^{\circ} \mathrm{C}$ for $48-72 \mathrm{~h}$. The neuraminidase activity in this and other materials was measured by the hemagglutination of rabbit erythrocytes using peanut agglutinin as described previously $(7,8) .1 \mathrm{U}$ of neuraminidase is defined as the amount of enzyme that hydrolyzes 1 $\mu$ mol of $N$-acetyl-neuraminic acid from human acid alpha ${ }_{1}$-glycoprotein per minute at $37^{\circ} \mathrm{C}(8)$.

We detected no difference in the substrate specificities of the neuraminidase produced by these two strains (data not shown). However, preparations from the Montalvania strain generally had higher titers of neuraminidase activity than those from the more widely studied $Y$ strain. In general, $10^{6}$ trypomastigotes of the $\mathrm{Y}$ strain yielded $\sim 7 \mu \mathrm{U}$ of activity,

1. Abbreviation used in this paper: DME, Dulbecco's modified Eagle's medium. 
a level exhibited by only $10^{4}$ trypomastigotes of the Montalvania strain. This study used both parasites of both strains in order to test whether any biological effects of this enzyme activity might be limited to a strain that produced this enzyme in high amounts.

Preparation of neonatal rat heart cell cultures. Myocardial cells were prepared by trypsin dissociation of hearts of 1-2-d-old rat pups, enriched for cardiac myocytes by differential adhesion, and plated at $2 \times 10^{5} / \mathrm{cm}^{2}$ (10). To retard the proliferation of nonmyogenic cells further, the medium was changed to DME containing fetal calf serum $(10 \%)$ and cytosine arabinoside $\left(10^{-5} \mathrm{M}\right)$ the day after initial plating. After $3 \mathrm{~d}$ of incubation in this medium, the cultures consisted mostly of contractile cells with the characteristic phase microscopic appearance of cardiac myocytes. Cells were generally used for experiments within $1 \mathrm{wk}$ of preparation.

Preparation of human saphenous vein endothelial cell cultures. These cells were prepared from unused portions of saphenous vein obtained during coronary artery bypass surgery. This use of normally discarded tissue was approved by the Human Investigation Review Committee of the New England Medical Center, Boston, MA. Endothelial cells harvested by treatment with collagenase ( $0.1 \%$ Worthington type II; Worthington [Cooper Biomedical, Inc.] Malvern, PA) were plated on tissue culture ware coated with human fibronectin $\left(1.5 \mu \mathrm{g} / \mathrm{cm}^{2}\right)$ and maintained in Medium 199 buffered with Hepes and supplemented with endothelial cell growth factor $(50 \mu \mathrm{g} / \mathrm{ml})$ and porcine heparin $(100 \mu \mathrm{g} / \mathrm{ml})$. These cells exhibited characteristic morphology, stained for von Willebrand factor in a rodlike or punctate distribution as determined by immunofluorescence or immunohistochemistry, and contained von Willebrand factor mRNA (data not shown). These cells were used for experiments in their third to fourth passage.

Metabolic labeling of sialic acid. To measure release of sialic acid from the myocardial cell surface, we used the ability of the cultured cells to incorporate isotopically labeled precursors of sialic acid into macromolecular glycoconjugates $(11,12)$. Intact cells labeled in this manner would be suitable substrates for determining neuraminidase activity. We used $\mathrm{N}$-acetyl-D-mannosamine $\left(6-{ }^{3} \mathrm{H}, 10 \mathrm{mCi} / \mathrm{mmol}\right.$, New England $\mathrm{Nu}$ clear, Boston, MA) and D-mannosine $\left(1-{ }^{14} \mathrm{C}, 45 \mathrm{mCi} / \mathrm{mmol}\right.$, Research Products International Corp., Mt. Prospect, IL) as precursors. Initial experiments showed that incorportion of tritiated $N$-acetyl-D-mannosamine $(5 \mu \mathrm{Ci} / \mathrm{ml})$ into material insoluble in perchloric acid $(0.2 \mathrm{M})$ was linear for up to $\sim 40 \mathrm{~h}$ and then tended to reach a plateau (data not shown). After a 48-h incubation with tritiated $N$-acetyl-D-mannosamine under these conditions, followed by four 1-h washing periods in fresh medium without radioactive precursor, $<20 \%$ of the radioactivity associated with the cell layer was in the form of material soluble in perchloric acid $(0.2 \mathrm{M})$. Thus, this procedure primarily labeled macromolecules. Incubation of cells labeled in this manner with purified neuraminidase from Vibrio cholera (5 $\mu \mathrm{U} / \mathrm{ml}$; Gibco, Grand Island, NY) released $19 \pm 3 \%$ of the radioactivity associated with the cell layer $(n=5)$. These results indicate that at least a fifth of the labeled macromolecules were accessible to an exogenous hydrolase.

Although $N$-acetyl-D-mannosamine is a direct and relatively specific precursor of sialic acid, transport of this acetylated sugar may be less efficient than transport of the less direct precursor D-mannosamine (11, 12). Therefore, we simultaneously compared labeling characteristics in dual isotope experiments with tritiated $N$-acetyl-D-mannosamine and ${ }^{14} \mathrm{C}$-labeled mannosamine. Rat myocardial cells were incubated in the presence of the tritiated precursor $(1 \mu \mathrm{Ci} / \mathrm{ml})$ and ${ }^{14} \mathrm{C}$-D-mannosamine $(0.5 \mu \mathrm{Ci} / \mathrm{ml})$ for $65 \mathrm{~h}$. After four 1-h washes with fresh medium, the monolayers were fractionated into material soluble and insoluble in perchloric acid $(0.2 \mathrm{M})$. While cultured myocardial cells took up much more radioactivity from the unacetylated sugar, the proportion of mannosamine incorporated into macromolecules was much less than in the case of $N$-acetyl-D-mannosamine (data not shown). Although $N$-acetylD-mannosamine did prove to be a more specific label for macromolecules, experiments were often performed using both precursors simultaneously. While we generally present results with $N$-acetyl-D-mannosamine, similar results were always obtained with the unacetylated mannosamine.

In some experiments, cellular proteins were labeled by incubation with ${ }^{14} \mathrm{C}$-tyrosine (uniformly labeled $460 \mathrm{mCi} / \mathrm{mM}, 0.2 \mu \mathrm{Ci} / \mathrm{ml}$ ). After the cell layers were washed as described above, $\sim 94 \%$ of the radioactivity was insoluble in perchloric acid $(0.2 \mathrm{M})$.

Chromatographic analysis of sialic acid. To determine the distribution of radioactivity released from metabolically labeled cardiac cells, the supernatants were analyzed by chromatography $(13,14)$. Material released from metabolically labeled cells was lyophilized, applied to columns ( 1 by $3 \mathrm{~cm}$ ) of Dowex $2 \times-8$ (in the formate form) and washed with water ( 10 column volumes). This effluent contained $<15 \%$ of the total radioactivity. The anionic material bound to the column was eluted with formic acid ( $2 \mathrm{M}, 10$ column volumes). Total recovery of radioactivity from this ion exchange column was $>89 \%$. The acid eluate was evaporated to dryness, dissolved in sulfuric acid $(6 \mathrm{~N}, 0.2 \mathrm{ml})$, and analyzed by high performance liquid chromatography on an Aminex HPX-87H organic acid column (Bio-Rad Laboratories, Richmond, CA) that was eluted isocratically with sulfuric acid $(3 \mathrm{mM})$ at $0.7 \mathrm{ml} / \mathrm{min}$. Fractions were analyzed for radioactivity by liquid scintillation spectrometry. The column was standardized with D-mannose, $N$-acetyl-D-mannosamine, $\mathrm{N}$-acetyl-neuraminic acid, and $\mathrm{N}$-glycolyl-neuraminic acid.

Galactose oxidase labeling of myocardial cells. Externally disposed, terminal galactosyl residues were labeled by the galactose oxidase method (15). To reduce any existing free aldehyde functions on the cell surface, monolayers were first exposed to sodium borohydride $(1 \mathrm{mM})$ in a buffered salt solution that lacked glucose $(\mathrm{NaCl}, 116 \mathrm{mM}$, Hepes, $16.5 \mathrm{mM}$, $\mathrm{NaHCO}_{3}, 10 \mathrm{mM}, \mathrm{KCl}, 5.4 \mathrm{mM}, \mathrm{CaCl}_{2}, 1.8 \mathrm{mM}, \mathrm{NaH}_{2} \mathrm{PO}_{4}, 1.0 \mathrm{mM}$, and $\mathrm{MgSO}_{4}, 0.8 \mathrm{mM}$ ). After washing, the cell layers were incubated under various conditions, then treated with galactose oxidase $(1 \mathrm{mg} / \mathrm{ml}$, Worthington (Cooper Biomedical, Inc.) for $1 \mathrm{~h}$. After washing, the monolayers were exposed to sodium borotritiide $(0.1 \mathrm{mCi} / \mathrm{ml})$ for 10 min at room temperature in the glucose-free buffer described above. After four washes in this buffer, the cell layer was dissolved in twofold concentrated Laemmli sample solvent (16). This extract was immediately boiled for $10 \mathrm{~min}$ (to inactivate susceptible proteases) and then stored frozen. Portions of this digest were analyzed by polyacrylamide gel electrophoresis on linear 5-15\% gradients using a discontinuous buffer system. After staining with Coomassie Blue, the gels were treated with Enhance (New England Nuclear) according to the manufacturer's instructions, dried, and exposed to X-omat $\mathrm{AR}-5$ film at $-70^{\circ} \mathrm{C}$ with a Cronex intensifying screen (Dupont Instruments, Wilmington, DE).

Histochemical visualization of peanut agglutinin binding sites. Tissue culture cells were fixed with buffered formalin (10\%). Endogenous peroxidase activity was blocked by incubating the cells in $\mathrm{H}_{2} \mathrm{O}_{2}(2 \%)$. The fixed cell layer was covered with a filtered liver powder solution at a concentration of $100 \mu \mathrm{g} / \mathrm{ml}$ in PBS for $10 \mathrm{~min}$ and then washed with PBS. The cells were then incubated for $30 \mathrm{~min}$ at room temperature with biotinylated peanut agglutinin $(20 \mu \mathrm{g} / \mathrm{ml})$, washed three times for $5 \mathrm{~min}$ with PBS, and then incubated with avidin-biotin-peroxidase complex as described previously (17). Horseradish peroxidase was visualized by incubation with PBS containing 3,3'diaminobenzidine tetrahydrochloride and $\mathrm{H}_{2} \mathrm{O}_{2}$. The slides were then washed in tap water for $5 \mathrm{~min}$, counterstained with methyl green, dehydrated, and coverslips were attached with permount. Positive staining was demonstrated by the dark diaminobenzidine- $\mathrm{H}_{2} \mathrm{O}_{2}$ reaction product.

\section{Results}

T. cruzi neuraminidase releases sialic acid from metabolically labeled myocardial cells. Soluble neuraminidase shed by intact $T$. cruzi trypomastigotes released radioactivity originating from both tritiated $\mathrm{N}$-acetyl-D-mannosamine and ${ }^{14} \mathrm{C}$-mannosamine at an approximately constant rate for $1 \mathrm{~h}$ at $37^{\circ} \mathrm{C}$ (Fig. 1). Subsequent experiments therefore generally measured release of radioactivity during the first hour when the rate reflected the apparent initial velocity of the reaction. Spontaneous release of radioactivity was always measured simultaneously in enzymefree blank conditions, and averaged $13 \pm 1.3 \%$ of the release induced by $V$. cholera neuraminidase $(5 \mu \mathrm{U} / \mathrm{ml}$, Gibco; 


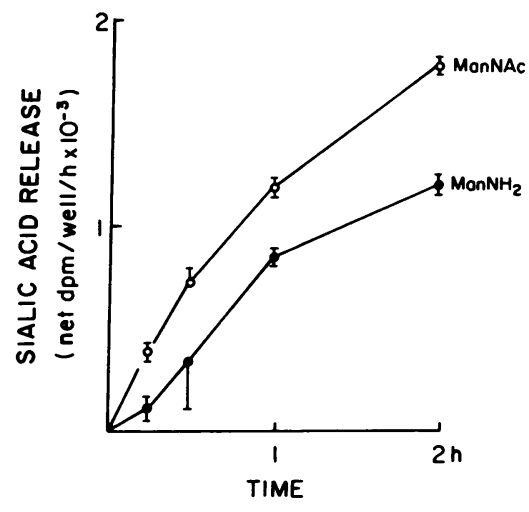

Figure 1. Time course of sialic acid release from myocardial cells by $T$. cruzi neuraminidase. Rat heart cells were labeled with ${ }^{3} \mathrm{H}-\mathrm{N}$-acetylD-mannosamine, $5 \mu \mathrm{Ci} / \mathrm{ml}$, and ${ }^{14} \mathrm{C}-\mathrm{D}$-mannosamine, $0.1 \mu \mathrm{Ci} / \mathrm{ml}$, on Costar 12 plates. $T$. cruzi neuraminidase was prepared in DME supplemented with insulin $\left(10^{-6}\right)$. The values reported are the difference of the spontaneous release at the same time point from the release in wells incubated with $T$. cruzi neuraminidase (mean \pm SE of 2-4 wells). The release of tritium counts is shown in open circles (ManNAc); release of ${ }^{14} \mathrm{C}$ is shown in closed circles $\left(\mathrm{ManNH}_{2}\right)$.

mean \pm SEM of average values from seven independent experiments each performed on 4-6 replicate wells). In preliminary experiments under these conditions, this concentration of the bacterial neuraminidase was maximally effective (data not shown).

In each of seven independent experiments, soluble neuraminidase from $T$. cruzi (either $\mathrm{Y}$ or Montalvania strains) caused net release of radioactivity. The activity of individual preparations of $T$. cruzi neuraminidase depends on such factors as time of storage and strain of origin. Accordingly, the amount of sialic acid release varied in individual experiments. In five experiments, the release induced by $T$. cruzi conditioned medium was measured in parallel with that produced by $V$. cholera neuraminidase $(5 \mu \mathrm{U} / \mathrm{ml})$. In these experiments, $T$. cruzi neuraminidase released from 10 to $113 \%$ (mean $67 \%$ ) of the radioactivity released by this constant amount of $V$. cholera enzyme.

Characterization of the radioactive products released by $T$. cruzi neuraminidase from metabolically labeled myocardial cells. The release of radioactivity from metabolically labeled cells might conceivably be due to proteolytic activity elaborated by $T$. cruzi or that may contaminate the $V$. cholera neuraminidase. To test this possibility, we measured simultaneously the release of radioactivity from myocardial cells labeled with both tritiated $N$ acetyl-D-mannosamine (to label sialic acid) and ${ }^{14} \mathrm{C}$-tyrosine (to label protein). Neuraminidase from either T. cruzi or $V$. cholera increased release of radioactivity originating from tritiated $N$ acetyl-D-mannosamine greater than sixfold, but did not release ${ }^{14} \mathrm{C}$-radioactivity from labeled proteins (Table I). In contrast, treatment with the proteolytic enzyme trypsin $(5 \mu \mathrm{g} / \mathrm{ml})$ increased the release of radioactivity associated with both the protein and the sugar label to the same extent. This result indicates that while trypsin cleaves glycopeptides containing both amino acids and carbohydrate residues from externally disposed glycoproteins, the neuraminidase activity released by $T$. cruzi selectively releases carbohydrate moieties.

To define further the chemical identity of the radioactive material(s) released by neuraminidase from myocardial cell surfaces labeled with $N$-acetyl-D-mannosamine, we analyzed these
Table I. Susceptibility to Hydrolysis by Neuraminidase or Trypsin of Sialic Acid and Proteins from the Surface of Metabolically Labeled Rat Myocardial Cells

\begin{tabular}{lcc}
\hline & $\begin{array}{l}\text { Sialic acid released* } \\
(3-\mathrm{H} \mathrm{dpm})\end{array}$ & $\begin{array}{l}\text { Protein released* } \\
(14-\mathrm{C} \mathrm{dpm})\end{array}$ \\
\hline $\begin{array}{l}\text { Control } \\
\text { T. cruzi } \text { neuraminidasef } \\
(10 \mu \mathrm{U} / \mathrm{ml})\end{array}$ & $306 \pm 30$ & $381 \pm 44$ \\
$\begin{array}{l}\text { V. cholera } \text { neuraminidase } \\
(10 \mu \mathrm{U} / \mathrm{ml})\end{array}$ & $2,174 \pm 27$ & $463 \pm 22$ \\
$\begin{array}{l}\text { Trypsin }(5 \mu \mathrm{g} / \mathrm{ml}) \\
\text { (n) }\end{array}$ & $1,963 \pm 210$ & $419 \pm 16$ \\
\hline
\end{tabular}

* Metabolic labeling of sialic acid with tritiated $N$-acetyl-D-mannosamine and of cell protein with $\mathrm{U}-{ }^{14} \mathrm{C}$-tyrosine was performed as described in Methods.

$¥ T$. cruzi neuraminidase was isolated from trypomastigotes of the $Y$ strain as described in Methods.

products chromatographically. The anion exchange resin Dowex $2 \times-8$ bound $93 \%$ of the radioactivity released by $T$. cruzi neuraminidase. The radioactive material eluted by formic acid ( 2 M) from this Dowex column co-migrated with authentic $N$-acetyl-neuraminic acid on an organic acid high performance liquid chromatography column (Aminex HPX-87H) (Fig. 2). These

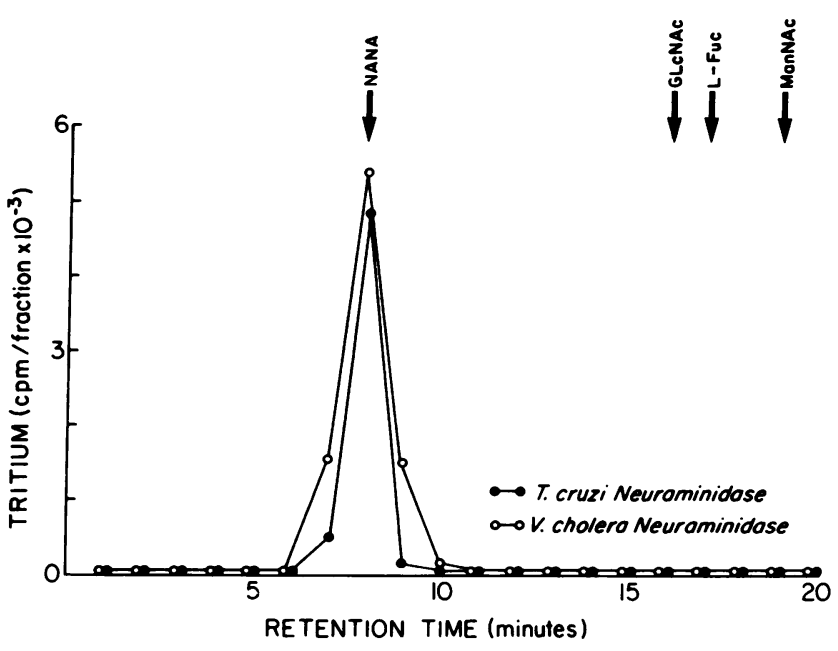

Figure 2. High performance liquid chromatography of material released from rat heart cells metabolically labeled with tritiated- $N$-acetylmannosamine. Neonatal rat myocardial cell cultures were labeled with tritiated $N$-acetyl-D-mannosamine, washed, and incubated with $T$. cruzi neuraminidase or $V$. cholera neuraminidase $(5 \mathrm{U} / \mathrm{ml}$ for $1 \mathrm{~h})$ as described in the Methods section. Greater than $85 \%$ of the radioactivity released into the medium bound to Dowex $2 \times-8$ at neutral $\mathrm{pH}$. The material eluted from the Dowex columns by formic acid (2 M) was applied to an Aminex HPX-87H high performance liquid chromatography column eluted as described in the Methods section. The recovery of the radioactivity from this column was $89 \%$ in the case of $T$. cruzi neuraminidase. The arrows show the positions where authentic standard sugars eluted during calibration runs under identical conditions. NANA, $N$-acetyl-neuraminic acid, GlcNAc, $N$-acetyl-D-glucosamine; Fuc, L-fucose; and ManNAc, $N$-acetyl-D-mannosamine. The radioactivity released by either $T$. cruzi neuraminidase (close circles) or purified neuraminidase from $V$. cholera (open circles) eluted as single peaks in the same position as authentic sialic acid (NANA). Similar results were obtained in an independent experiment. 
experiments confirm that sialic acid is the major radioactive species released by $T$. cruzi neuraminidase from myocardial cells metabolically labeled with $N$-acetyl-D-mannosamine.

Intact living $T$. cruzi trypomastigotes release sialic acid from myocardial cells. The foregoing experiments indicated that neuraminidase shed by $T$. cruzi can remove sialic acid from the myocardial cell surface. It was also important to determine if the intact parasite could desialylate myocardial cells. Live $T$. cruzi trypomastigotes released metabolically labeled sialic acid from rat heart cells in three independent experiments with the $Y$ strain. In a representative experiment, net release of sialic acid with $5 \times 10^{8}$ cells $/ \mathrm{ml}$ was $1,268 \pm 362 \mathrm{dpm} / \mathrm{h}$. Incubation of rat heart cells with trypomastigotes of the myotropic Montalvania strain also induced release of sialic acid in a concentration dependent manner (Fig. 3). These results demonstrate that intact, living $T$. cruzi can release sialic acid from the surface of beating rat myocardial cells.

Noninfective amastigote forms of $T$. cruzi fail to release sialic acid from myocardial cells. Neuraminidase production by $T$. cruzi depends on the developmental stage of the organism. The infective trypomastigote form expresses a high titer of activity while noninfective epimastigotes, found in the insect vector and under some conditions in vitro, express much smaller amounts of this activity (7). Amastigotes, the intracellular replicative form of $T$. cruzi, neither infect cells nor produce neuraminidase. We isolated amastigotes and trypomastigotes from bovine aortic smooth muscle cells infected simultaneously with the Montalvania strain of $T$. cruzi. We then exposed metabolically labeled rat myocardial cells to optimum concentrations of either live trypomastigotes or an equal number of amastigotes $\left(10^{8}\right.$ organisms $/ \mathrm{ml}$ ). The amastigotes did not release sialic acid, while $T$. cruzi trypomastigotes or purified $V$. cholera neuraminidase did remove sialic acid from the myocardial cells under identical conditions (Fig. 4).

Specific myocardial cell surface glycoprotein substrates of $T$. cruzi neuraminidase. The above experiments demonstrated release of sialic acid from externally disposed glycoconjugates on the myocardial cell surface. To characterize further the substrates for $T$. cruzi neuraminidase, we used galactose oxidase labeling,

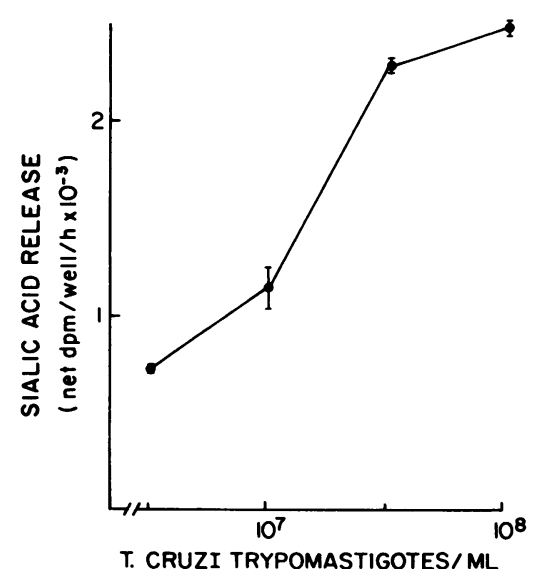

Figure 3. Concentration dependence of sialic acid release from myocardial cells by $T$. cruzi trypomastigotes. Rat heart cells labeled with ${ }^{3} \mathrm{H}-\mathrm{N}$-acetyl-D-mannosamine were incubated with live $T$. cruzi trypomastigotes of the Montalvania strain for $1 \mathrm{~h}$. Data reported are mean $\pm \mathrm{SE}$ of the mean of acid-insoluble radioactivity released from 4 to 6 cultures in each condition.

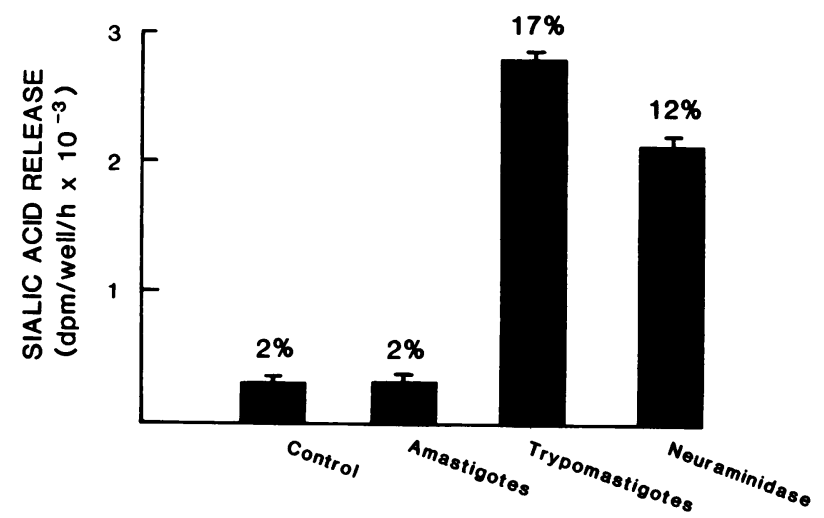

Figure 4. Comparison of neuraminidase activity in $T$. cruzi trypomastiges and amastigotes. Rat heart cells labeled with ${ }^{3} \mathrm{H}-\mathrm{N}$-acetyl-D-mannosamine were incubated with amastigotes or trypomastigotes of the Montalvania strain $\left(10^{8} \mathrm{cells} / \mathrm{ml}\right)$ prepared in parallel. The data reported are mean $\pm S E$ of 4-6 observations. The numbers above the bars indicate the percentage of the total radioactivity that was released during $1 \mathrm{~h}$. The control condition was tissue culture medium without parasite cells. The purified neuraminidase was from $V$. cholera $(5 \mu \mathrm{U} / \mathrm{ml})$.

a technique that specifically demonstrates newly desialylated glycoproteins (16). Myocardial cell cultures were first treated with sodium borohydride to reduce all accessible free aldehyde groups. When neuraminidase removes a terminal sialic acid residue from an $\mathrm{N}$ - or $\mathrm{O}$-linked complex oligosaccharide chain of a glycoprotein, it uncovers a galactose or $N$-acetyl-D-galactosamine residue. An hydroxyl group of the newly exposed sugar can then be oxidized to the corresponding aldehyde by treatment

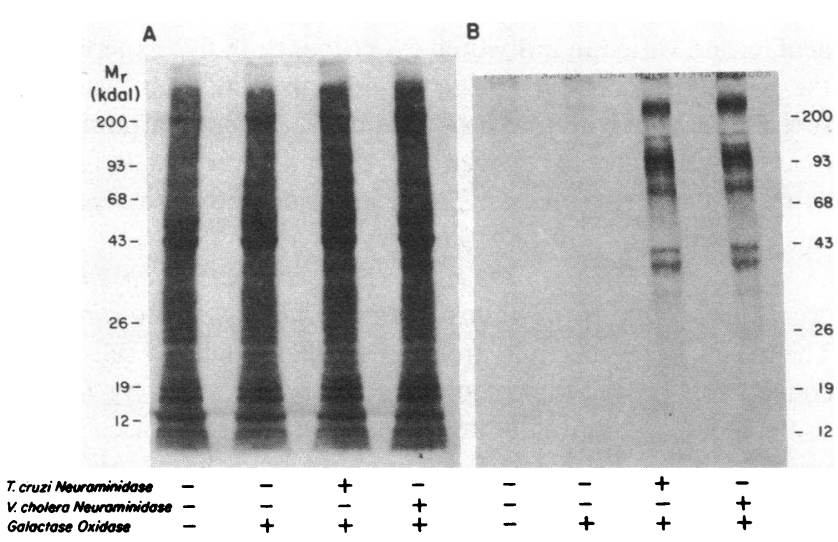

Figure 5. T. cruzi neuraminidase desialylates myocardial cell glycoproteins demonstrated by galactose oxidase labeling. Myocardial cell cultures were incubated in medium with or without $T$. cruzi neuraminidase or $V$. cholera neuraminidase $(10 \mu \mathrm{U} / \mathrm{ml})$ for $1 \mathrm{~h}$ before galactose oxidase surface labeling. Extracts of the labeled cell layers were electrophoresed on a polyacrylamide gradient gel (5-15\%). A photograph of the Coomassie Blue stained gel shows that equal amounts of protein were applied to each lane $(A)$. The fluorograph of the same gel is shown in $B$. In each panel, the conditions were (from left to right): (1) control, treated with neither neuraminidase nor galactose oxidase; (2) control, not treated with neuraminidase but incubated with galactose oxidase; (3) culture incubated with $T$. cruzi neuraminidase and then galactose oxidase; and (4) culture treated with $V$. cholera neuraminidase and then galactose oxidase. An independent experiment showed similar results. kdal, kilodalton. 


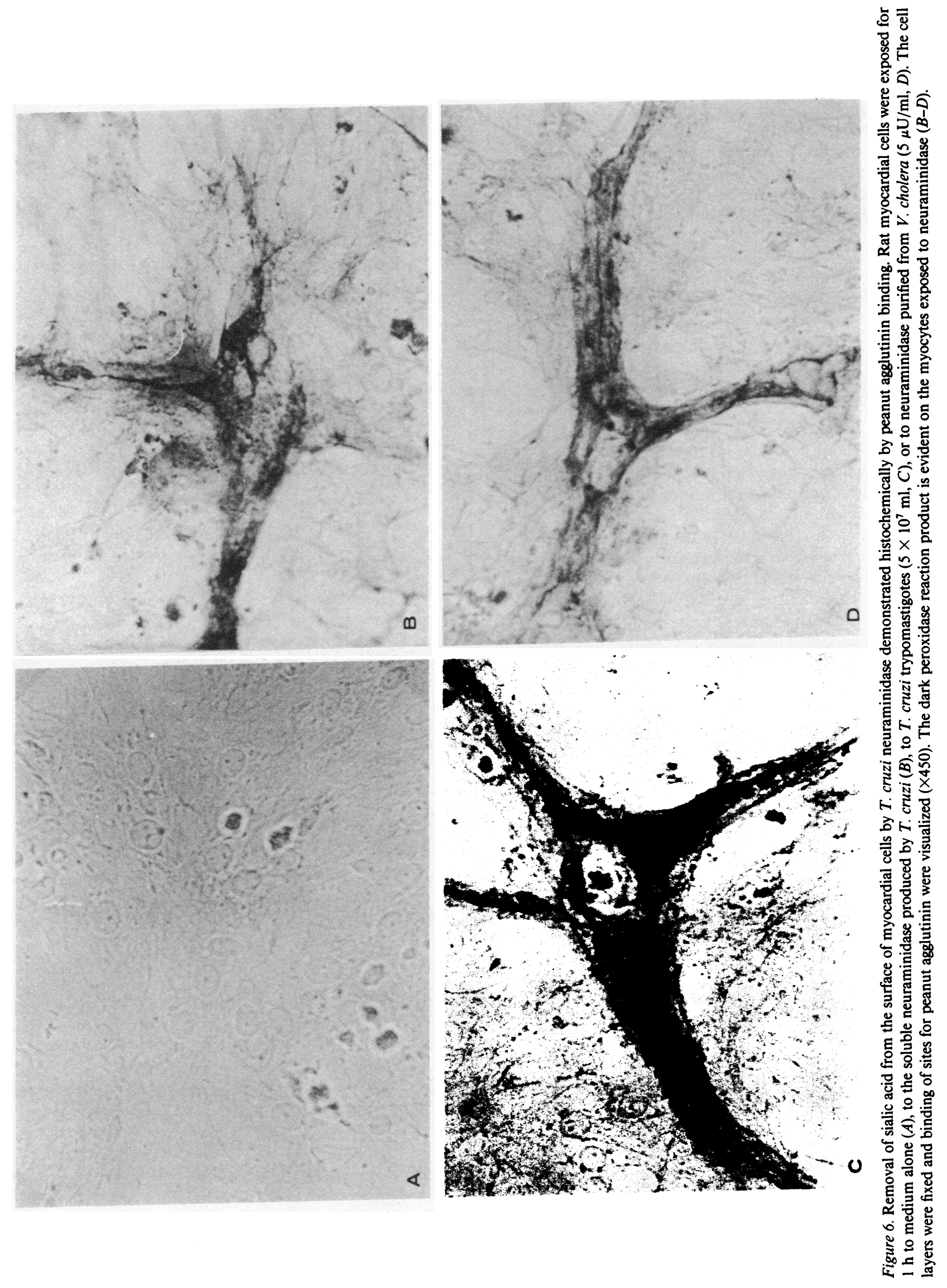


with the enzyme galactose oxidase. This newly formed aldehyde group is then reduced by treatment with sodium borotritiide, which introduces two tritium atoms into each desialylated position in the oligosaccharide chain. Extracts of cultures labeled in this manner after neuraminidase treatment were analyzed by electrophoresis (Fig. 5). Each lane of this gel contained equal amounts of protein stainable by Coomassie Blue (Fig. $5 \mathrm{~A}$ ). Cell cultures that had not been treated with neuraminidase showed no tritiated protein bands (Fig. $5 \mathrm{~B}$ ). However, cultures treated with neuraminidase from either $T$. cruzi or $V$. cholera showed labeled protein bands in a similar pattern (Fig. $5 B$, righthand lanes). One of these bands had an apparent molecular weight $>200,000$. This electrophoretic behavior is similar to that of the well-known cell surface glycoprotein fibronectin.

Histochemical evidence for desialylation of myocardial cell surface molecules. To verify the results obtained with metabolic labeling and galactose oxidase labeling experiments we used an independent technique. Galactose residues uncovered by desialylation of oligosaccharide chains will bind peanut agglutinin (17). The appearance of binding sites for this galactose-binding lectin was visualized by an avidin-biotin immunoperoxidase linked technique. Cultures of rat myocardial cells not treated with neuraminidase showed no binding of peanut agglutinin. However, after incubation with neuraminidase from either $T$. cruzi or $V$. cholera, myocardial cell cultures showed abundant binding of this lectin (Fig. 6).

T. cruzi neuraminidase also releases sialic acid from adult human vascular endothelial cells. Blood-borne trypomastigotes in the mammalian host must cross the endothelial barrier to invade peripheral tissues such as myocardium. In addition, desialylation of endothelium can increase platelet adhesion to arteries (18). Therefore, we determined whether $T$. cruzi neuraminidase could also remove sialic acid from vascular endothelial cells. Neuraminidase from $T$. cruzi did release metabolically labeled sialic acid from adult human saphenous vein endothelial cells (Fig. 7), as well as from bovine aortic endothelial cells (data not shown). This result was confirmed by histochemical studies that showed binding of peanut lectin to neuraminidase-treated but not to control cultures of adult human endothelial cells (Fig. 8).

\section{Discussion}

Death due to Chagas' disease is usually caused by chronic cardiac involvement (1). The etiologic agent of this disease, $T$. cruzi, is an obligate intracellular parasite. During the acute phase of Chagas' disease the parasites enter and multiply within myocardial cells, and their progeny must exit from these cells in order to propagate the infection. Before encountering the myocardial and other potential target cells, the blood-borne trypomastigote must traverse the vascular endothelium. For the parasite to enter or exit myocardial or endothelial cells, it must contact two structures rich in functionally important sialylated glycoproteins: the basement membrane or glycocalyx, and the plasmalemma itself (19-22).

Sialoglycoconjugates of the cell surface play many important roles in physiology and pathology (23). In some preparations of cardiac tissue, negatively charged sialic acid residues appear to modulate the access of calcium ions to the sarcolemma $(19,22$, 24-26). Desialylation of mammalian cells can also activate the alternative pathway of complement (27).

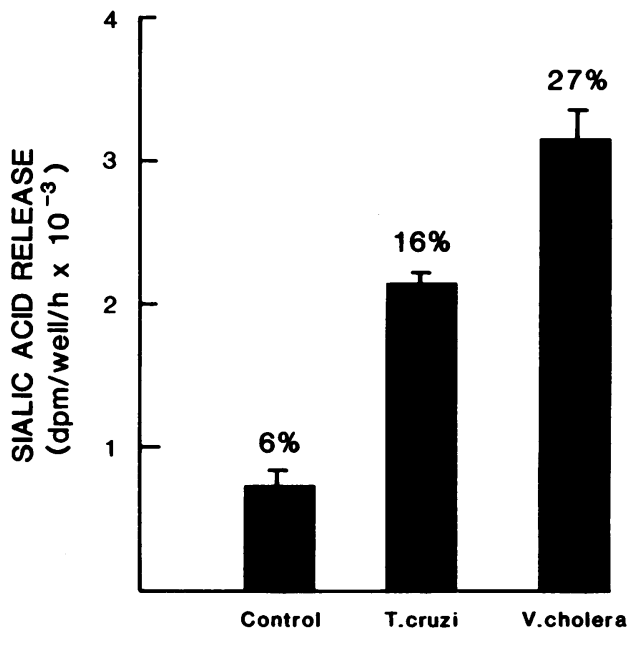

Figure 7. T. cruzi neuraminidase releases sialic acid from human vascular endothelial cells. Human saphenous vein endothelial cell cultures labeled with ${ }^{3} \mathrm{H}-\mathrm{N}$-acetyl-D-mannosamine were incubated for $\mathbf{1 ~ h}$ with neuraminidase shed by $T$. cruzi (Montalvania strain, $7 \mu \mathrm{U} / \mathrm{ml}$ ) or from $V$. cholera $(10 \mu \mathrm{U} / \mathrm{ml})$. The bars show release of sialic acid in the medium $(n=4$, mean \pm SEM). The numbers above the bars indicate the percentage of the total radioactivity released during the hour incubation. The control condition was tissue culture medium without parasite cells. An independent experiment gave similar results.

Sialyl residues on the lumenal surface of vascular endothelium can also influence the interactions of blood cells with the vessel wall in important ways (28). For example, treatment with neuraminidase promotes the adhesiveness of platelets (18) and granulocytes (29) to endothelium. Desialylation of the endothelial surface could contribute to the platelet aggregation and thrombosis within coronary arteries that accompany cardiac fibrosis in mice infected experimentally with $T$. cruzi $(30,31)$. In addition, sialyl residues may account for the selective adhesion of circulating lymphocytes to specialized venular endothelial cells in peripheral lymph nodes (32).

We previously demonstrated that during infection of mice with $T$. cruzi, desialylation of erythrocytes occurs in vivo in relation to the degree of parasitemia (7). Desialylated erythrocytes are liable to sequestration perhaps via the asialoglycoprotein pathway, and are subject to lysis by the alternative pathway of complement $(27,33)$. Therefore, this action of $T$. cruzi neuraminidase probably explains the anemia associated with acute $T$. cruzi parasitemia (34). However, alteration by $T$. cruzi of the surfaces of myocardial and endothelial cells could be more relevant to development of the later and often lethal chronic phase of Chagas' disease.

For this reason, it was of interest to determine whether the activity of this enzyme of parasite origin was limited to erythrocytes, or if it could also hydrolyze sialylated glycoconjugates present on the surfaces of these pathologically important target cells. By a variety of independent criteria, we found that $T$. cruzi can indeed desialylate the surfaces of both of these cardiovascular cell types in vitro. Soluble neuraminidase shed by infective $T$. cruzi trypomastigotes removed sialic acid from these cells as shown by release of free sialic acid, lectin binding, and cytochemistry.

More importantly, living $T$. cruzi trypomastigotes also released sialic acid from intact beating myocardial cells. This de- 


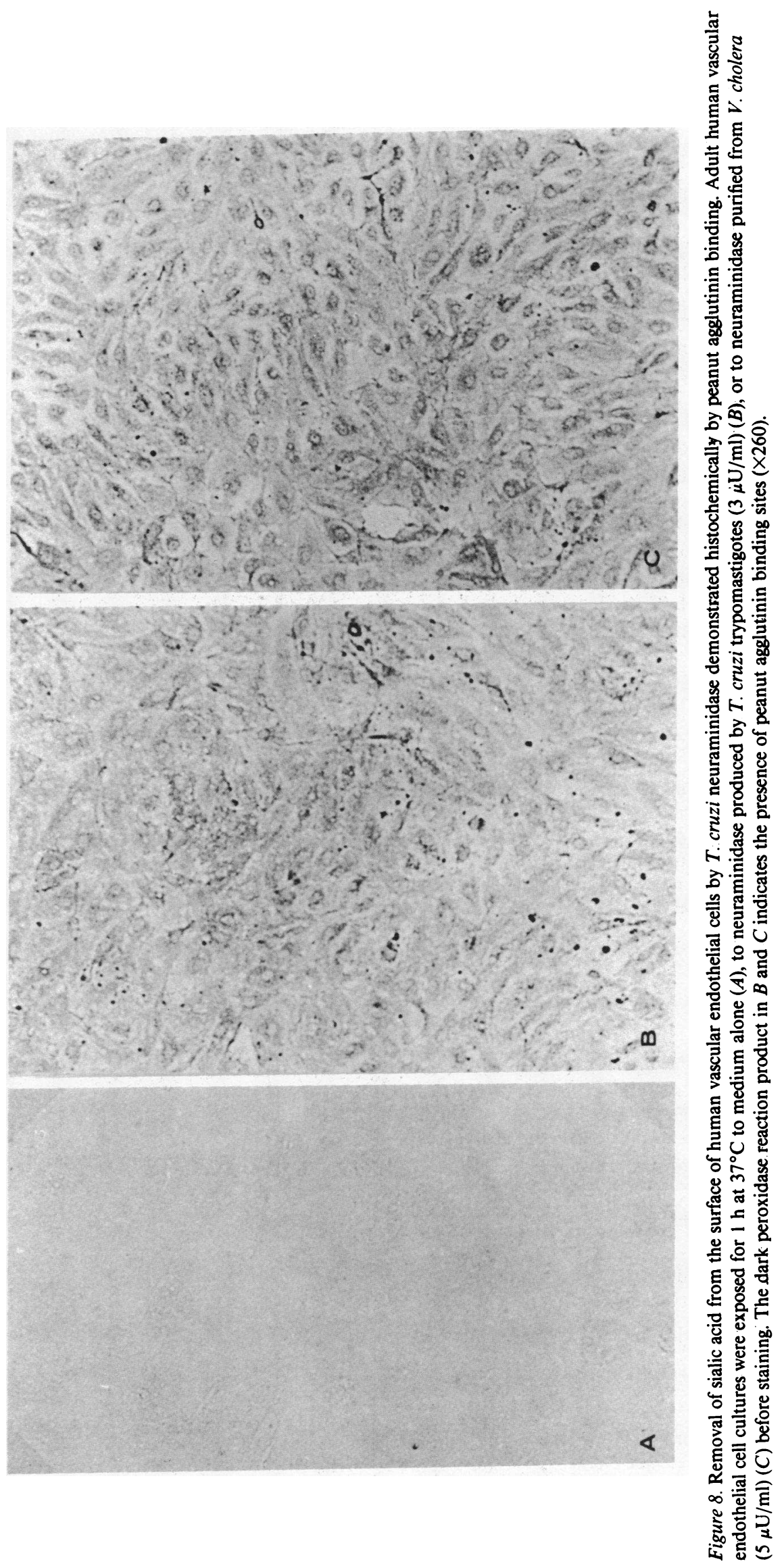


sialylation was selective, since the noninvasive, noninfectious amastigote form of this parasite which lacks neuraminidase activity did not free sialic acid from the host cells. Only the developmental form of $T$. cruzi that can infect the mammalian host cell caused desialylation. This result is consistent with involvement of the parasite neuraminidase in the initial host-trypanosome interaction at the cellular level. A precedent for a role for neuraminidase activity in the pathogenesis of an intracellular infection is found in myxovirus. Neuraminidase on the surface of influenza virus is not only an immunogen, but can influence tissue tropism and aid the viral particle to enter or leave the host cell as well $(35,36)$.

This study demonstrated a novel biochemical change in the surface of cardiovascular cells produced by infective forms of $T$. cruzi. The precise role that $T$. cruzi neuraminidase might play in the pathophysiology of Chagas' disease is not yet clear. However, the results presented here are consistent with a role for this enzyme in the critical early interaction of this parasite with important mammalian target cells. This initial interaction of host and parasite cells is a necessary precursor to development of the late cardiac disease. The chemical alteration of the host cell surface by the parasite that was demonstrated here should stimulate future work to delineate the potential role of $T$. cruzi neuraminidase activity in the variety of mechanisms implicated in the production of Chagasic cardiovascular disease (37-39).

\section{Acknowledgments}

We thank Maria Janicka, Paula M. Cullinane, and Vibha Goyal for technical assistance, Cynthia M. Heim for secretarial and administrative help, and Dr. Jose Marcos Ribeiro, Dr. Gerald Keusch, and Dr. Sheldon M. Wolff for useful discussions.

This study was supported by a grant from the Charlton Fund of Tufts University (to Dr. Libby), American Heart Association grant-in aid 80922 (to Dr. Libby), National Institutes of Health grant 1-RO1-AI18102 (to Dr. Pereira).

\section{References}

1. Brener, Z., and Z. A. Andrade, editors. 1979. Trypanosoma cruzi e doenca de Chagas. Guanabara Koogan, Rio de Janeiro. 1-463.

2. Nogueira, N., and Z. Cohn. 1977. Trypanosoma cruzi: mechanism of entry and intracellular fate in mammalian cells. J. Exp. Med. 143: $1402-1420$.

3. Nogueira, N. 1983. Host and parasite factors affecting the invasion of mononuclear phagocytes by Trypanosoma cruzi. In Cytopathology of Parasitic Disease. Pitman Books, London (Ciba Foundation Symposium 99). 52-73.

4. Neva, F. A., M. F. Malone, and B. R. Myers. 1961. Factors influencing the intracellular growth of Trypanosoma cruzi in vitro. Am. J. Trop. Med. Hyg. 10:140-154.

5. Bioul-Marchand, M., J.-M. Jadin, R. F. Steiger, and B. Thierry. 1980. Multiplication of Trypanosoma cruzi in a mouse myocardial cell line. J. Parasitol. 66:1050-1052.

6. Henriquez, D., R. Piras, and M. M. Piras. 1981. The effect of surface membrane modifications of fibroblastic cells on the entry process of Trypanosoma cruzi trypomastigotes. Mol. Biochem. Parasitol. 2:359366.

7. Pereira, M. E. A. 1983. A developmentally regulated neuraminidase activity in Trypanosoma cruzi. Science (Wash. DC). 219:1444-1446.

8. Pereira, M. E. A. 1983. A rapid and sensitive assay for neuramin- idase using peanut lectin hemagglutination: application to Vibrio cholera and Trypanosoma cruzi. J. Immunol. Methods. 63:25-34.

9. Libby, P., and K. V. O'Brien. 1983. Culture of quiescent vascular smooth muscle cells in a defined serum-free medium. J. Cell. Physiol. 115:217-223.

10. Libby, P. 1984. Long-term culture of contractile mammalian heart cells in a defined medium that limits non-muscle cell proliferation. J. Mol. Cell. Cardiol. 16:803-811.

11. Corfield, A. P., and R. Schauer. 1979. Current aspects of glycoconjugate biosynthesis. Biol. Cell. 36:213-226.

12. Gilfix, B. M., and B. D. Sanwal. 1983. Metabolic labelling of oligosaccharide chains of glycoproteins in a rat myoblast cell line and its lectin resistant mutants. Can. J. Biochem. Cell Biol. 61:1129-1132.

13. Schauer, R. 1978. Characterization of sialic acids. Methods Enzymol. 50:64-89.

14. Silver, H. K. B., K. A. Karim, M. J. Gray, and F. A. Salinar. 1981. High performance liquid chromatography quantitation of $\mathrm{N}$-acetyl neuraminic acid in malignant melanoma and breast carcinoma. J. Chromatogr. 4:1219-1221.

15. Gahmberg, C. G., and S.-I. Hakomori. 1973. External labeling of cell surface galactose and galactosamine in glycolipid and glycoprotein of human erythrocytes. J. Biol. Chem. 248:4311-4317.

16. Laemmli, U. K. 1970. Cleavage of structural proteins during the assembly of bacteriophage T4. Nature (Lond.). 277:680-685.

17. Alroy, J., A. A. Ucci, and M. E. A. Pereira. 1983. Lectins: histochemical probes for specific carbohydrate residues. In Diagnostic Immunology. R. A. DeLellis, editor. Masson, Inc., New York. 67-88.

18. Gorog, P., I. Schraufstatter, and G. V. R. Born. 1982. Effect of removing sialic acids from endothelium on the adherence of circulating platelets in arteries in vivo. Proc. R. Soc. Lond. B. Biol. Sci. 214:471480.

19. Langer, G. A. 1978. The structure and function of the myocardial cell surface. Am. J. Physiol. 235:H461-H468.

20. Pelikan, P., M. A. Gimbrone, Jr., and R. S. Cotran. 1979. Distribution and movement of anionic cell surface sites in cultured human vascular endothelial cells. Atherosclerosis. 32:69-80.

21. Simionescu, M., N. Simionescu, J. E. Silbert, and G. E. Palade. 1981. Differentiated microdomains on the luminal surface of the capillary endothelium. II. Partial characterization of their anionic sites. J. Cell Biol. 90:614-621.

22. Woods, W. T., K. Imamura, and T. N. James. 1982. Electrophysiological and electron microscopic correlations concerning the effects of neuraminidase on canine heart cells. Circ. Res. 50:228-239.

23. Schauer, R. 1981. Chemistry, metabolism, and biologic functions of sialic acids. Adv. Carbohydr. Chem. Biochem. 40:131-234.

24. Frank, J. S., G. A. Langer, L. M. Nudd, and K. Seraydarian. 1977. The myocardial cell surface, its histochemistry, and the effect of sialic acid and calcium removal on its structure and cellular ionic exchange. Circ. Res. 41:702-714.

25. Isenberg, G., and U. Klockner. 1980. Glycocalyx is not required for slow inward calcium current in isolated rat heart myocytes. Nature (Lond.). 284:358-360.

26. Harding, S. E., and J. Halliday. 1980. Removal of sialic acid from cardiac sarcolemma does not affect contractile function in electrically stimulated guinea pig left atria. Nature (Lond.). 286:819-821.

27. Brown, E. J., K. A. Joiner, and M. M. Frank. 1983. Interaction of desialated guinea pig erythrocytes with the classical and alternative pathways of guinea pig complement in vivo and in vitro. J. Clin. Invest. 71:1710-1719.

28. Gorog, P., and J. D. Pearson. 1984. Surface determinants of low density lipoprotein uptake by endothelial cells. Atherosclerosis. 54:2129.

29. Hoover, R. L., R. T. Briggs, and M. J. Karnovsky. 1978. Adhesive interaction between polymorphonuclear leukocytes and endothelial cells in vitro. Cell. 14:423-438.

30. Rossi, M. A., S. Goncalves, and R. Ribeiro-Dos-Santos. 1984. Experimental Trypanosoma cruzi cardiomyopathy in BALB/c mice. The 
potential role of intravascular platelet aggregation in its genesis. Am. J. Pathol. 114:209-216.

31. Factor, S. M., S. Cho, M. Wittner, and H. Tanowitz. 1985. Abnormalities of the coronary microcirculation in acute murine Chagas' disease. Am. J. Trop. Med. Hyg. 34:246-253.

32. Rosen, S. D., M. S. Singer, T. A. Yednock, and L. M. Stoolman. 1985. Involvement of sialic acid on endothelial cells in organ-specific lymphocyte recirculation. Science (Wash. DC). 228:1005-1007.

33. Jancik, J., and R. Schauer. 1974. Sialic acid-a determinant of the life-time of rabbit erythrocytes. Hoppe-Seyler's Z. Physiol. Chem. 355:395-400.

34. Cardoso, J. E., and Z. Brenner. 1980. Hematological changes in mice infected with Trypanosoma cruzi. Mem. Inst. Oswaldo Cruz Rio De J. 75:97-104.
35. Sugiura, A., and M. Ueda. 1980. Neurovirulence of influenza virus in mice. I. Neurovirulence of recombinants between virulent and avirulent strains. Virology. 101:440-449.

36. Palese, P., K. Tobita, M. Ueda, and R. W. Compans. 1974. Characterization of temperature sensitive influenza virus mutants defective in neuraminidase. Virology. 61:397-410.

37. Andrade, Z. A. 1983. Mechanisms of myocardial damage in Trypanosoma cruzi infection. In Cytopathology of Parasitic Disease. Pitman Books, London (Ciba Foundation Symposium 99). 214-233.

38. Sadigursky, M., A. M. Acosta, and C. A. Santos-Buch. 1982. Muscle sarcoplasmic reticulum antigen shared by a trypanosoma cruzi clone. Am. J. Trop. Med. Hyg. 31:934-941.

39. Hudson, L. 1983. Trypanosoma cruzi: the immunological consequence of infection. J. Cell. Biochem. 21:299-304. 